\title{
NGAL for Preeclampsia: How Sure are We?
}

\author{
Sachin Gupta ${ }^{1}$, Deeksha S Tomar ${ }^{2}$ () \\ Indian Journal of Critical Care Medicine (2021): 10.5005/jp-journals-10071-23969
}

Pregnancy-related acute kidney injury (PR-AKI) is a life-threatening obstetric complication and accounts for $30-60 \%$ of all the complications. Among various risk factors for the development of AKI, preeclampsia plays a major role and it complicates almost $6-8 \%$ of pregnancies and is associated with maternal morbidity and mortality. ${ }^{1}$ The diagnostic criteria for defining AKI in pregnancy are also not validated as the existing criteria like Risk, Injury, Failure, Loss, End-stage (RIFLE) and Acute Kidney Injury Network (AKIN) have not been used for pregnant patients. The normal physiological changes in pregnancy and increase in glomerular filtration rate reduce creatinine in pregnancy, ${ }^{2}$ hence making the validity of these scores doubtful.

The other issue is the validity of the existing biomarkers in predicting AKI in pregnancy. The recently most studied biomarker for AKI prediction in the general population is neutrophil gelatinaseassociated lipocalin (NGAL). ${ }^{3}$ The elevated levels of NGAL in plasma and/or urine have been found to be superior than other conventional biomarkers. ${ }^{4}$ The surprising co-relation has been seen between high NGAL levels and prediction of preeclampsia. The study by D'Anna et al. ${ }^{5}$ showed that NGAL should be used as a prediagnostic test for the prediction of preeclampsia in high-risk pregnancies, although the predictive value of NGAL for AKI in pregnant patients was doubtful. So do we start using NGAL for preeclampsia prediction? Is it a by-chance finding? This needs to be answered.

In the current issue of the Indian Journal of Critical Care Medicine, Tyagi et al. ${ }^{6}$ evaluated the epidemiology of AKI in preeclampsia who are admitted to the intensive care unit (ICU) and also the predictive value of NGAL for AKI in preeclamptics. A sample size of 52 patients was included in the study. The AKI was recorded as per the existing definition of RIFLE and AKIN criteria. They also measured NGAL levels at the time of admission. Almost $48.1 \%$ (25) of patients had AKI during the stay out of which 14 had stage 1, 9 had stage 2, and 2 had stage 3 severity. A total of seven patients died. The AKI patients had prolonged ICU and hospital stay and were associated with higher mortality. The NGAL levels did not differentiate between AKI and non-AKI patients ( $p=0.722)$ as well as among survivors and nonsurvivors ( $p=0.859)$. But the interesting finding was increased NGAL levels were associated with a higher incidence of eclampsia $(p=0.018)$.

The incidence of AKI in the study presented was higher as compared to the study by Bentata et al. ${ }^{1}$ as they took only RIFLE criteria for defining AKI, whereas the authors here defined AKI as per Kidney Disease Improving Global Outcomes criteria. The authors did not define that whether the urine output criteria or the serum creatinine criteria were used to define AKI in their study. Secondly, the exact incidence of AKI in patients with preeclampsia is not clear as most of the studies have quoted the incidence of AKI in pregnancy with various risk factors ${ }^{7}$ like hypertension, HELLP
1,2Department of Critical Care Medicine, Narayana Superspeciality Hospital, Gurugram, Haryana, India

Corresponding Author: Sachin Gupta, Department of Critical Care Medicine, Narayana Superspeciality Hospital, Gurugram, Haryana, India, Phone: +91 9873240734, e-mail: dr_sachin78@yahoo.co.in

How to cite this article: Gupta S, Tomar DS. NGAL for Preeclampsia: How Sure are We? Indian J Crit Care Med 2021;25(9):972-973.

Source of support: Nil

Conflict of interest: None

(hemolysis, elevated liver enzymes, low platelet count) syndrome and anemia. Any pregnant female with preeclampsia getting admitted to ICU is a critically ill patient and will have almost a similar incidence of AKI as for any other critically ill patient.

The search for an ideal biomarker for predicting AKI is still on although NGAL has been utilized for this purpose. The interesting co-relation has been between NGAL values and the prediction of preeclampsia and its severity. Kim et al. ${ }^{8}$ compared the NGAL values in preeclampsia and normotensive patients and found that NGAL values were significantly higher in preeclamptics and it also correlated with the disease severity. A similar observation was presented by Moyake et al. ${ }^{9}$ where they measured NGAL levels at baseline and after 24 hours and concluded that NGAL levels are not a suitable predictive test for AKI in preeclampsia patients, but it provides reliable predictive value for eclampsia. From these two studies and a couple of others, it can be said that NGAL may be a useful marker for PR-AKI and also for preeclampsia, but it is not able to differentiate between the two subsets if present together, and this becomes an issue with the predictive value of a biomarker. 8,10 In a recent study by Törnblom et al., ${ }^{11}$ urinary NGAL (UNGAL) was assessed for the utility of prediction of AKI in septic patients, but they concluded that UNGAL alone correlated poorly with AKI, and it should not be followed in critically ill septic patients for AKI prediction.

The use of NGAL for preeclampsia and eclampsia prediction looks appealing, but one has to understand that NGAL levels increase in the state of inflammatory conditions associated with epithelial cell injury like pelvic inflammatory disease, chronic obstructive pulmonary disease, malignancies of breast, lungs, and colon. ${ }^{12}$ NGAL is also released from maternalfetal interface and is thought to be released when there is uterine vasoconstriction as happens in preeclampsia. Although it may appear to be a useful marker for the prediction of eclampsia, still its role in other inflammatory conditions should also be evaluated before we name it as an ideal biomarker in obstetrics.

() Jaypee Brothers Medical Publishers. 2021 Open Access This article is distributed under the terms of the Creative Commons Attribution 4.0 International License (https://creativecommons.org/licenses/by-nc/4.0/), which permits unrestricted use, distribution, and non-commercial reproduction in any medium, provided you give appropriate credit to the original author(s) and the source, provide a link to the Creative Commons license, and indicate if changes were made. The Creative Commons Public Domain Dedication waiver (http://creativecommons.org/publicdomain/zero/1.0/) applies to the data made available in this article, unless otherwise stated. 


\section{OrCID}

Sachin Gupta ㄴ https://orcid.org/0000-0001-8663-9507

Deeksha S Tomar 이 https://orcid.org/0000-0001-6099-3559

\section{References}

1. Bentata Y, Housni B, Mimouni A, Azzourzi A, Abouqal R. Acute kidney injury related to pregnancy in developing countries: etiology and risk factors in an intensive care unit. J Nephrol 2012;25:764-775. DOI: 10.5301/jn.5000058

2. Fakhouri F, Vercel C, Fremeaux-Bacchi V. Obstetric nephrology: AKI and thrombotic microangiopathies in pregnancy. Clin J Am Soc Nephrol 2012;7:2100-2106. DOI: 10.2215/CJN.13121211.

3. Haase M, Bellomo R, Devarajan P, Schlattmann P, Haase-Fielitz $A_{\text {; }}$ NGAL Meta-analysis Investigator Group. Accuracy of neutrophil gelatinase-associated lipocalin (NGAL) in diagnosis and prognosis in acute kidney injury: a systematic review and meta-analysis. Am J Kidney Dis 2009;54(6):1012-1024. DOI: 10.1053/j.ajkd.2009.07.020. PMID: 19850388.

4. Haase-Fielitz A, Bellomo R, Devarajan P, Story D, Matalanis G, Dragun $D$, et al. Novel and conventional serum biomarkers predicting acute kidney injury in adult cardiac surgery - a prospective cohort study. Crit Care Med 2009;37(2):553-560. DOI: 10.1097/ CCM.0b013e318195846e. PMID: 19114878.

5. D'Anna R, Baviera G, Giordano D, Todarello G, Corrado F, Buemi M. Second trimester neutrophil gelatinase-associated lipocalin as a potential prediagnostic marker of preeclampsia. Acta Obstet Gynecol Scand 2008;87(12):1370-1373. DOI: 10.1080/00016340802464463. PMID: 18951213.
6. Tyagi A, Yadav P, Salhotra R, Das S, Singh PK, Garg D. Acute Kidney Injury in Severe Preeclamptic Patients admitted to Intensive Care Unit: Epidemiology and Role of Serum Neutrophil Gelatinase-associated Lipocalcin. Indian J Crit Care Med 2021;25(9):1013-1019.

7. Conti-Ramsden Fl, Nathan HL, De Greeff A, Hall DR, Seed PT, Chappell LC, et al. Pregnancy-related acute kidney injury in preeclampsia: risk factors and renal outcomes. Hypertension 2019;74(5):1144-1151. DOI: 10.1161/HYPERTENSIONAHA.119.13089. PMID: 31564161; PMCID: PMC6791560.

8. Kim SM, Park JS, Norwitz ER, Jung HJ, Kim BJ, Park CW, et al. Circulating levels of neutrophil gelatinase-associated lipocalin (NGAL) correlate with the presence and severity of preeclampsia. Reprod Sci 2013;20(9):1083-1089. DOI: 10.1177/1933719113477480. PMID: 23439619; PMCID: PMC3745712.

9. Moyake N, Buchmann E, Crowther NJ. Neutrophil gelatinaseassociated lipocalin as a diagnostic marker of acute kidney injury in pre-eclampsia. J Obstet Gynaecol Res 2016;42(11):1483-1488. DOI: 10.1111/jog.13088. PMID: 27559014.

10. Patel M, Sachan R, Gangwar R, Sachan P, Natu S. Correlation of serum neutrophil gelatinase-associated lipocalin with acute kidney injury in hypertensive disorders of pregnancy. Int J Nephrol Renovasc Dis 2013;6:181-186. DOI: 10.2147/IJNRD.S45523.

11. Törnblom S, Nisula S, Petäjä L, Vaara ST, Haapio M, Pesonen E, et al. FINNAKI study group. Urine NGAL as a biomarker for septic AKI: a critical appraisal of clinical utility-data from the observational FINNAKI study. Ann Intensive Care 2020;10(1):51. DOI: 10.1186/s13613020-00667-7. PMID: 32347418; PMCID: PMC7188747.

12. Xu S, Venge P. Lipocalins as biochemical markers of disease. Biochim Biophys Acta 2000;1482(1-2):298-307. DOI: 10.1016/s01674838(00)00163-1. PMID: 11058770. 